\title{
PERSPECTIVAS HISTÓRICAS E EPISTEMOLÓGICAS SOBRE PRISÃO E ESCOLA NO SISTEMA PENITENCIÁRIO' ${ }^{1}$
}

\author{
Edmar Souza das Neves \\ Mesaque Silva Correia
}

\section{INTRODUÇÃO}

O estudo sistemático referente à cultura organizacional da instituição prisional e a assistência educacional à pessoa presa constitui um amplo desafio aos pesquisadores. No Brasil, os trabalhos acadêmicos ainda são escassos, o que acaba dificultando o conhecimento do tema por parte de estudantes, professores, pesquisadores e comunidade em geral.

Torna-se, então, bastante oportuna a publicação de pesquisas que tratem deste assunto, uma vez que o estudo sistemático dessas temáticas possibilitam a qualificar e aperfeiçoar políticas educacionais desenvolvidas no sistema penitenciário brasileiro, principalmente no que concerne às políticas de execução penal, que privilegiam a reinserção social daqueles que, tendo cumprido suas penas, devem e necessitam integrar-se à sociedade, assim como favorecem a estruturação de processos educativos às pessoas privadas de liberdade.

Todavia, é preciso observar que a intenção de analisar o sistema prisional, com o objetivo de desvendar seu modo de organização e a forma como se processa sua rotina é uma tarefa que deve ser realizada com muita prudência, pois o espaço carcerário apresenta-se como um solo melindroso, e, a cultura prisional é singular. De acordo com Santos (2011, p. 119), “[...] investigar essa realidade implica em considerar os processos de exclusão e, simultaneamente, enfrentar a forma mais evidente da contradição entre a formação e a desumanização do ser humano".

Para o mundo científico, a função política da prisão encontra, em meio a discursos nem sempre dialógicos, de um lado, os que acreditam que a prisão deve punir e ser mais rigorosa, de outro, os que defendem a sua manutenção, considerando os direitos das pessoas presas. Contudo, também existem os defensores de formas alternativas de prisão como as penas reparadoras, estas visando mais a reparação do delito do que o encarceramento para coibir, o envolvimento do indivíduo com o mundo da criminalidade.

\footnotetext{
${ }^{1}$ DOI: $10.29388 / 978-65-86678-21-5-f .57-78$
} 
É essencial que tenhamos em vista que a prisão é uma instituição política. Sua função social, após a formação do Estado liberal, é de recuperação dos indivíduos, e sua matéria-prima o tratamento penal e as assistências que estão preconizadas na Lei de Execução Penal (BRASIL, 1984), devem contribuir para reinserir a eles na sociedade brasileira.

Dessa forma, este estudo ensaístico reflete o interesse dos pesquisadores e a necessidade sociopolítica e científica de estruturação de debates mais aprofundados sobre a prisão e a escola localizada em seu interior. O objetivo, portanto, aqui é apresentar e analisar as perspectivas históricas e epistemológicas sobre prisão e escola que faz parte do sistema penitenciário.

\section{PRESSUPOSTOS POLÍTICO-LEGAIS DA ASSISTÊNCIA EDUCA- CIONAL AOS SUJEITOS PRIVADOS DE LIBERDADE}

Não por acaso, as políticas públicas foram pensadas na tentativa de contribuir com o processo de reinserção social da pessoa privada de liberdade e a assistência educacional representa o mecanismo que vem sendo defendido por instituições nacionais e internacionais, no contexto dos processos educativos à pessoa presa.

O documento intitulado: Regras Minimas para o Tratamento de Reclusos, elaborado no $1^{\circ}$ Congresso das Nações Unidas sobre Prevenção do Crime e Tratamento de Delinquentes, realizado em Genebra, no ano de 1955, estabeleceu a educação como garantia da pessoa privada de liberdade. No ítem Educação e Recreio, Princípios Orientadores n ${ }^{\circ} 77$, encontra-se posto que: "Serão tomadas medidas para melhorar a educação de todos os presos em condições de aproveitá-la, incluindo instrução religiosa nos países em que isso for possível. A educação de analfabetos e presos jovens será obrigatória, prestando-lhe à administração especial atenção" (CENTRO DOS DIREITOS DO HOMEM DAS NAÇÕES UNIDAS, 2019).

Outro evento importante para garantia da educação nos estabelecimentos penais, foi a Conferência Mundial sobre Educação para Todos, realizada em Jomtien, Tailândia, em 1990, em que se estabeleceu, na World Declaration on Education for all: Meeting Basic Learning Needs, no início do Art. 10 "Cada pessoa - criança, jovem e adulto - pode beneficiar-se de oportunidades educacionais planejadas para atender suas necessidades básicas de aprendizagem [...]” (UNESCO, 1990, p. 3).

Em correspondência, propõe a difusão e universalização da Educação Básica, e, o princípio de educação ao longo da vida, inclusive para as pessoas 
privadas de liberdade. É assim que se segue a Resolução no 20/1990, do Conselho Econômico e Social das Nações Unidas, que trata da educação nas prisões e recomenda aos Estados Membros os seguintes princípios:

a) A educação nas prisões deve visar ao desenvolvimento da pessoa como um todo, tendo em mente a história social, econômica e cultural do preso; b) Todos os presos devem ter acesso à educação, inclusive programas de alfabetização, educação fundamental, formação profissional, atividades criativas, religiosas e culturais, educação física e desportos, educação superior e biblioteca; c) Deve-se envidar todos os esforços destinados a incentivar os presos a participarem ativamente de todos os aspectos da educação; d) Todos os envolvidos na administração e gestão da prisão devem facilitar e apoiar ao máximo a instrução; e) A instrução deve ser um elemento essencial do regime carcerário; não se deve desencorajar os presos que participam de programas aprovados de educação formal; f) A formação profissional deve visar ao maior desenvolvimento do indivíduo e deve ser sensível às tendências de mercado; g) Deve-se atribuir um papel significativo às atividades criativas e culturais, pois tem um potencial especial no que diz respeito a permitir que os presos desenvolvam-se e se expressem; h) Sempre que possível, os presos devem ser autorizados a participarem da educação fora da prisão; i) Nos locais onde a educação tiver de ocorrer dentro da prisão, a comunidade externa deve participar ao máximo do processo; j) Deve-se disponibilizar as verbas, equipamentos e pessoal docente necessários para permitir que os presos recebam uma educação adequada (RESOLUÇÃO no 1990/20 apud ABREU, 2008, p. 33-34).

A Lei de Execução Penal - LEP, sancionada no dia 11 de julho de 1984, em que pese esse documento ser um marco na garantia do direito à educação das pessoas presas, estabelece a educação como uma das práticas assistenciais. Na seção V do seu Capítulo II. Da Assistência, do Art. 17 ao 21 (BRASIL, 2008), define sobre a assistência educacional no sistema penitenciário, o que destacamos:

Art. 17. A assistência educacional compreenderá a instrução escolar e a formação profissional do preso e do internado.

Art. 18. O ensino de primeiro grau será obrigatório, integrando-se no sistema escolar da unidade federativa.

Art. 19. O ensino profissional será ministrado em nível de iniciação ou de aperfeiçoamento técnico. 
Parágrafo único. A mulher condenada terá ensino profissional adequado à sua condição.

Art. 20. As atividades educacionais podem ser objeto de convênio com entidades públicas ou particulares, que instalem escolas ou ofereçam cursos especializados.

Art. 21. Em atendimento às condições locais, dotar-se-á cada estabelecimento de uma biblioteca, para uso de todas as categorias de reclusos, provida de livros instrutivos, recreativos e didáticos (BRASIL, 2008, p. 23).

$\mathrm{Na}$ LEP, a assistência educacional à pessoa presa é amplamente prevista como um direito no inciso VII do Art. 41. Nesse mesmo artigo, constam como parte dos direitos dos indivíduos reclusos: assistência material, à saúde, jurídica, educacional, social e religiosa, entre outros (BRASIL, 2008). Já os Art. 17, 18, 19, 20 e 21 desta lei regulamentam como se dará a assistência educacional, na qual encontramos certa restrição às oportunidades educacionais no interior das instituições penais, se comparadas aos cursos ofertados aos jovens e adultos presos.

Até junho de 2011, a população carcerária tinha direito apenas de curso de ensino fundamental, considerando que LEP não incluía o curso de ensino médio ou superior às pessoas presas como parte da assistência educacional, o que foi alterado com a homologação da Lei no 13.163 de 9 de setembro de 2015 (BRASIL, 2015). Este fato aponta para uma divergência entre a LEP e a CF, considerando que as normas constitucionais postulam como dever do Estado a "progressiva universalização do ensino médio gratuito" desde o ano de 1996, conforme o Art. 20 ${ }^{\circ}$ inciso I da Emenda Constitucional no 14 (BRASIL, 1996).

Além disso, ainda na Lei de Execução Penal é possível identificar uma valorização do trabalho em detrimento do direito à educação. Em especial no Art. 126 por assegurar a remição de pena através do trabalho, mas não garantia o mesmo para aqueles que tiveram acesso à educação (BRASIL, 2008). Essa valorização do trabalho frente à educação, além de não incentivar a procura por escolarização, reforça a sua descaracterização como um direito, colocando a educação formal como um privilégio concedido aos detentos. Da mesma forma, reforça a ideia de que ela não tem potencial para contribuir com a declamada reintegração social, que começou a mudar a partir da Lei n ${ }^{\circ} 12.433$ de 29 de junho de 2011, a qual estabeleceu a remição de parte do tempo da pena pelo es tudo ou trabalho (BRASIL, 2011).

Como bem postula Julião (2012), mesmo diante de muitos dispositivos legais que preconizam a educação como uma assistência ao sujeito privado de 
liberdade e das diversas frentes de luta edificadas por militantes da área em prol da garantia da educação nos estabelecimentos prisionais, a oferta da escolarização nas prisões do nosso país ainda é restrita e entendida por alguns atores sociais como um privilégio. Concordamos, nesse aspecto, com a crítica de Teixeira (2007, p 14) de que "[...] a educação não pode ser entendida como privilégio, benefício ou, muito menos, recompensa oferecida em troca de um bom comportamento [...]", mas como um direito previsto na legislação brasileira.

Pode-se dizer que a falta de compreensão quanto ao papel social da educação nas prisões e a ausência de políticas públicas educacionais no sistema prisional têm impossibilitado que a escola contribua com a formação cidadã do sujeito preso. De mesmo modo, impede que se possa desenvolver uma ação educativa fundamentada na cultura escolar e também no que se pode aplicar da cultura prisional na educação formal.

O conceito de cultura prisional pode ser encontrado nos estudos do sociólogo americano Donald Clemmer (1960), do sociólogo e criminologista Gresham Sykes (1999) e do jurista Augusto Frederico Gaffée Thompson (2002). Com base nos estudos desenvolvidos por esses autores é possível afirmar que as pessoas que ficam privadas de liberdade em estabelecimentos prisionais vivenciam o fenômeno da prisonização, o que significa que são levados a aderir, em maior ou menor grau, ao modo de pensar, hábitos, costumes e cultura geral da penitenciária, isto é, são levados a internalizar os padrões simbólicos existentes na comunidade prisional.

Clemmer (1960) conceitua cultura prisional como sendo as manifestações inerentes ao fenômeno da prisonização, englobando práticas e sistemas de comportamento, tradições, histórias e costumes, hábitos e modos de pensar, sistema de sinais ou palavras, leis, normas, ideias, opiniões, atitudes em defesa/ contra ou referente a lares, família, educação, trabalho, governo, prisões, polícia, juízes, presos, diretor de presídio, guardas, armas de fogo, cela, repreensão, muros, maquinários, livros, somas de dinheiro, roubo, furto, homicídio, extorsão, violação, estupro, sexo, amor, honestidade, tormento e outros.

A cultura escolar diz respeito às normas instituídas pela escola da prisão e a forma como o currículo escolar é materializado no decorrer do processo educativo, assim como a rotina pela qual a pessoa presa é submetida no interior da escola do cárcere.

Vasquez (2008, p. 83-84), por sua vez, define cultura escolar como sendo: 
O conjunto formado pelos conhecimentos, comportamentos e sistemas de valores que balizam a execução dos direitos do ser humano em cumprimento de pena privativa de liberdade, que é manifestado ou compartilhado pelo corpo docente e técnico administrativo, como tentativa de fomentar a reflexão quanto à forma de interação entre os membros da comunidade escolar prisional, ou ainda, como tentativa de incultar as relações sociais ou interpessoais necessárias para conviver entre os membros da "sociedade livre".

Outros estudos realizados por Onofre (2011), Julião (2012), FalcadePereira e Asinelli-Luz (2014), com a intenção de discutir possibilidades e limites da educação no sistema penitenciário no Brasil, mostraram as dificuldades de desenvolvimento de programas educacionais de caráter emancipatório em virtude da estrutura funcional da prisão, cuja cultura organizacional, é disciplinar. Em linhas gerais, enfatizam que a oferta de educação nas prisões, além de não se ter saído das experiências de educação básica, muitas delas realizadas precariamente e ainda persiste o número elevado de encarcerados analfabetos e/ou que não concluíram o Ensino Fundamental.

Tal situação contraria as experiências de oferta de educação prisional em alguns países, por exemplo, no sistema penitenciário argentino, que além de ofertar educação básica ao sujeito preso, registra experiências consolidadas de ensino superior em algumas prisões.

É por isso que Julião (2015) observa em relação ao Brasil:

Infelizmente, não diferente das políticas sociais em geral no nosso país, vivemos também na política de educação para os jovens e adultos em situação de restrição e privação de liberdade as contradições e agruras do descompasso entre o legal e o instituído na prática, tão comum na cultura política do nosso Estado (JULIÃO, 2015, p. 33).

O descompasso entre o legal e a prática é o que prevalece, mesmo a legislação brasileira determinando que o sistema de ensino deve assegurar, gratuitamente, aos jovens e adultos que não puderam concluir seus estudos na idade regular, cursos de ensino fundamental e médio pela educação de jovens e adultos (BRASIL, 1996), o que abrange os jovens e adultos presos.

Onofre (2011) e Julião (2012) reconhecem que a educação ofertada nas escolas das prisões, como modalidade da educação básica para jovens e adultos, deve investir em uma proposta educacional que leve em consideração as particularidades, especificidades e características dos sujeitos privados de liberdade e 
ofereça a formação docente continuada, para que a cultura e as especificidades da escola do cárcere possam ser contempladas nos projetos pedagógicos e nos planos de ensino.

Portanto, para que a escola da prisão cumpra sua função social é necessário acolhimento, reconhecimento e refúgio do cárcere, construção de interações e identidade longe do crime, espaço de vivência de experiências, com ainda, trocas e de cooperação para formação de cidadãos críticos e emancipados e, por consequência, mais humanizados.

\section{PRISÃO E ESCOLA COMO INSTITUIÇÕES DE SEQUESTRO}

Michel Foucault (1926-1984) foi um filósofo francês, que exerceu grande influência sobre os intelectuais contemporâneos. Com o falecimento de Jean-Paul Sartre em 1980, Foucault tornou-se o mais famoso intelectual francês. Era possuidor de um pensamento transversal por atravessar campos como os da Filosofia, História, Sociologia, Psicologia e Direito. Ficou conhecido por suas posições contrárias às políticas de determinadas instituições, em especial nas áreas da psiquiatria, da medicina e do penitenciarismo, e por suas ideias sobre a evolução histórica da sexualidade.

Ganhou notoriedade por sublinhar a similaridade dos modos de tratamento conferidos aos grandes grupos de indivíduos que vivem à margem da sociedade, como loucos, prisioneiros, alguns grupos de estrangeiros, soldados e crianças. Nas concepções foucaultianas, tais grupos têm em comum o fato de serem vistos com desconfiança e excluídos por uma regra de confinamento em instituições com instalações seguras, especializadas, construídas e organizadas em modelos semelhantes (asilos, presídios, quartéis e escolas), inspiradas no modelo monástico, instituições que ele chamou de "disciplinares" (FOUCAULT, 1977).

Alguns estudiosos de sua obra afirmam existir certa controvérsia no desenvolvimento de seu pensamento, por mudar as orientações de suas investiga ções algumas vezes, o que identificaria a existência de três Foucault: um que produz uma arqueologia, que seria a primeira fase do trabalho foucaltiano, ele próprio tendo denominado uma de suas obras Arqueologia do Saber, como se desenvolvesse um método arqueológico de pensamento; um segundo em que en-

\footnotetext{
${ }^{2}$ Filósofo, escritor e crítico francês, que ficou conhecido como representante do existencialismo. Acreditava que os intelectuais têm de desempenhar um papel ativo na sociedade. Era um artista militante, que apoiou causas políticas de esquerda com a sua vida e a sua obra. Ver em: COHEN-SOLAL, A. Sartre: uma Biografia. Trad. de Milton Persson. 2.ed. Porto Alegre: L\&PM Editores, 2008.
} 
tra em cena o genealogista, mergulhando nas questões relacionadas ao poder, influenciado pelo pensamento de Friedrich Nietzsche ${ }^{3}$, em busca da genealogia do poder. Por fim, um terceiro Foucault que se dedica a pensar as questões da ética, quando ele retoma os antigos estudos de história da sexualidade e encontra nos gregos e romanos toda uma maneira de se viver e tematizar a vida. Entretanto, o próprio Foucault não visualizava essas mudanças de percurso, sua preocupação central sempre foi o problema do sujeito.

Esse problema do sujeito atravessa a sua obra com diferentes reflexões. O sujeito tematizado na sua relação com o saber, na fase arqueológica; o sujeito pensado na sua relação com o poder, na fase genealógica, e o sujeito visto na sua relação consigo mesmo, na fase da ética, na qual ele pensa a estética da exis tência. O fato é que, nesse percurso, com seus estudos sobre o Saber, o Poder e o Homem, ajudou a compreender a dinâmica de instituições sociais como hospícios, prisões e escolas.

Mergulhando na raiz de seu pensamento, observamos que um dos maiores interesses de Foucault eram as formas de controle exercidas pelas instituições sociais. Ao analisar os processos disciplinares adotados por instituições como hospícios, escolas e prisões identificou como sua estrutura organizacional acabava por controlar aqueles que eram nelas colocados, por meio da imposição de padrões ditos "normais" de conduta, dado que com a emergência da sociedade capitalista houve a necessidade de se produzir corpos dóceis para o trabalho e as mentes submissas à sujeição aos padrões culturais hegemônicos.

Para entender a dinâmica do poder, Foucault (1977) se deteve em estudar as estruturas organizacionais das prisões, porque, segundo ele, nas prisões o poder não se esconde nem se mascara; ao contrário, pode se manifestar em seu estado bruto, em suas formas mais excessivas, uma vez que na prisão ele encontra sua inteira justificativa como um poder moral, em nome do bem e da ordem é permitido punir.

Muito embora não acredite que o poder e a dominação são originários de uma única fonte controladora, em sua concepção, eles seriam exercidos todos os dias em diferentes níveis. Não existindo relação de poder que não seja acompanhada da criação de um poder e de um conhecimento e vice-versa, e essa seria a possibilidade, para os sujeitos, de agirem contra o que não quer ser, para então pensar outras possibilidades para o mundo em que se vive.

\footnotetext{
${ }^{3}$ Filósofo, filólogo, crítico cultural, poeta e compositor alemão do século XIX. Seus escritos se detiveram sobre questões que envolviam a religião, a moral, a cultura contemporânea, filosofia e ciência, exibindo uma predileção pela metáfora, a ironia e o aforismo. Ver em: BROBJER, T. Nietzsche's philosophical context: an intellectual biography, p. 42.
} 
Ou seja, para Foucault é possível lutar contra a dominação representada por padrões de pensamento e comportamento, só não se pode ser imune e se livrar completamente das relações de poder, já que:

O poder deve ser analisado como algo que circula, ou melhor, como algo que só funciona em cadeia. Nunca está localizado aqui ou ali, nunca está nas mãos de alguns, nunca é apropriado como uma riqueza ou um bem. O poder funciona e se exerce em rede. Nas suas malhas os indivíduos só circulam, mas estão sempre em posição de exercer este poder, são sempre centros de sua transmissão (FOUCAULT, 1989, p. 183).

Segundo a ótica foucaultiana, a prisão representa a forma mais perversa do poder, pois colocar alguém na prisão e sequestrar a sua liberdade constituía em uma maneira de controlar as pessoas. Na prisão, o domínio sobre o outro age de forma excessiva e intensa. À luz dessa afirmação, Foucault compreende que a prisão.

[...] Ela se constituiu fora do aparelho judiciário, quando se elaboraram, por todo corpo social, os processos para repartir os indivíduos, fixá-los e distribuí-los espacialmente, classificá-los, tirar deles o máximo de tempo, e o máximo de forças, treinar seus corpos, codificar seu comportamento contínuo, mantê-los numa visibilidade sem lacuna, formar em torno deles um aparelho completo de observação, registro e anotações, constituir sobre eles um saber que se acumula e se centraliza (FOUCAULT, 1977, p. 207).

Acreditava esse autor que a prisão, mesmo que fosse exercida com base em preceitos legais, era uma instituição social pensada pela burguesia com objetivo de controlar, dominar e fragilizar os meios de cooperação e a solidariedade do proletariado. Por esse motivo, "a prisão é o coroamento do processo que torna os sujeitos dóceis” (FOUCAULT, 1977, p. 34). Entretanto, enquanto instituição disciplinar, de plena vigilância e punição, não diminui a delinquência e muito menos recompõe o ser social, ao contrário, provoca reincidência.

Outro ponto que chama a atenção nas considerações de Foucault em relação à prisão é a afirmação de que o modelo de funcionamento dessa instituição favorece a organização de delinquentes solidários entre si, hierarquizados e preparados para cumplicidades futuras; que as condições externas à prisão favorecem a reincidência. 
Foucault (1977) é contundente na afirmação de que a prisão localizada no seio da sociedade capitalista exerce a função de produzir sujeitos delinquentes ao produzir a ilegalidade concentrada, controlada e desarmada, tornando-se, dessa forma, útil ao sistema. Observa ainda que a origem do delinquente não está no sujeito, mas na forma de organização social em que reina um jogo de forças.

Ele enfantiza (1977, p. 274):

Não há então natureza criminosa, mas jogos de força que, segundo a classe a que pertencem os indivíduos, os conduzirão ao poder ou à prisão: pobres, os magistrados de hoje sem dúvida povoariam os campos de trabalhos forçados; e os forçados, se fossem bem nascidos, 'tomariam assento nos tribunais e aí distribuiriam justiça’.

Dessa forma, Foucault denuncia a ineficácia do sistema penitenciário, afirmando que a prisão instituída modernamente se distanciou do conceito imaginado por seus pensadores. Há de se considerar que a prisão enquanto uma instituição social não cumpre seu papel, mas apenas a função corretiva. Pois a prisão como instituição de sequestro, construída historicamente, ao invés de reduzir a criminalidade, introduz os condenados em carreiras criminosas.

Assim como a prisão, Foucault (1977) se deteve em investigar e analisar a instituição escola. Ao analisar o fenômeno da disciplina, o centro de sua análise se dá em torno da instituição escolar. No decorrer de suas investigações sobre essa instituição, encontrou situação de vigilância, adestramento do corpo e da mente, isto é, formas de exercer o poder e produzir um determinado tipo de sujeito e de sociedade. Nesse sentido, escolas, assim como hospitais, quartéis e prisões, eram vistas por Foucault como "instituições de sequestro", onde os indivíduos seriam retirados do seu espaço social e internados por um longo período para mudar sua conduta e disciplinar o seu comportamento.

Enquanto instituição disciplinar, a escola desenvolve técnicas para a produção de corpos dóceis. Segundo ele, no interior das escolas, o corpo entra numa maquinaria de poder em que os mecanismos disciplinares o desarticulam e o recompõem da maneira mais conveniente ao sistema, produzindo corpos submissos, exercitados e disciplinados. Por meio de sua estrutura organizacional e de suas técnicas disciplinares, a escola é arquitetada para que os sujeitos possam ser distribuídos no espaço, o que Foucault chamou de encarceramento mais especificamente, a localização imediata, ou o quadriculamento, para que se evite a aglomeração, para que se possa vigiar o comportamento de cada sujeito. 
Aponta Foucault que, além de distribuir os sujeitos, é necessário localizá-los no espaço, fazendo com que cada indivíduo se defina por seu lugar na série, individualizando os corpos por meio de uma localização que os distribui e os faz circular numa rede de relações. Dessa maneira, a escola deve ser dividida em séries e classes que individualizam os alunos em filas, o que facilita a vigilância e o controle. Nesse sentido, "[...] a sala de aula formaria um grande quadro único, com entradas múltiplas, sob o olhar cuidadosamente 'classificador' do professor” (FOUCAULT, 1977, p. 135). A distribuição das classes em fileiras, com alunos em ordem e uniformizados, tem como objetivo garantir a obediência e uma melhor utilização do tempo, com a criação de espaços funcionais e hierárquicos:“[...] trata-se de organizar o múltiplo, de se obter um instrumento para percorrê-lo e dominá-lo, trata-se de lhe impor uma "ordem" (FOUCAULT, 1977, p. 135).

Além disso, o autor também assinalou que nas instituições escolares controlam-se as atividades pelo horário, fazendo com que todo o tempo o corpo fique empregado no trabalho e que cada gesto e ação seja monitorada. A disciplina, então, é a própria microfísica do poder, instituída para o controle e sujeição do corpo, tendo como objetivo produzir corpos dóceis e úteis (FOUCAULT, 1989).

$\mathrm{Na}$ epistemologia foucaultina encontramos três tipos de técnicas disciplinares. A primeira delas é a vigilância hierárquica, que funciona como poder sobre o corpo alheio, composto por redes integrais de relações e exercido por dispositivos observatórios que obrigam pelo olhar. A segunda é a sanção normalizadora, que está na essência de todo sistema disciplinar, que tem como objetivo enquadrar tudo aquilo que se encontra inadequado aos contratos sociais a ideia é reduzir os desvios e os corrigir. A terceira e última técnica, que combinam as duas primeiras, é o exame, que constitui um controle normativo, uma vigilância que permite qualificar, classificar e punir, fazendo de cada indivíduo um caso, como registro geral, e transformando-o num objeto para ser vigiado e controlado.

Daí compreende-se que a disciplina é o elemento essencial para garantir o aprendizado. É por meio da disciplina dos estudantes e dos professores que o sistema educativo avança. Portanto, manter o professor em um regime disciplinar como de operários fabris, produzindo resultado e impondo ao aluno seu poder para usar o máximo de proveito, torna-se o objetivo almejado.

$\mathrm{Na}$ perspectiva foucaultina, a escola apresenta configuração parecida com o ambiente carcerário, em sua disposição física, seus mecanismos de disciplinarização, sua organização hierárquica, sua vigilância constante. A analogia 
física das escolas e às prisões, derivam de sua estrutura arquitetônica, com suas classes organizadas lado a lado sem nenhuma comunicação, grades nas janelas, refeitório comunitário, muros altos e com grades, portões sem nenhuma visibilidade do lado externo.

A escola segue a mesma arquitetura panóptica por constituir “[...] um espaço fechado, recortado, vigiado em todos os seus pontos, onde os indivíduos estão inseridos num lugar físico em que os menores movimentos são controlados onde todos os acontecimentos são registrados [...]" (FOUCAULT, 1977, p. 174). A cultura organizacional e de vigilância permite ao gestor escolar um maior controle sobre todas as movimentações na escola, pois quem está no corredor, quem vai ao banheiro, a classe "indisciplinada" e qualquer outra movimentação que fuja da normalidade.

Acrescenta Foucault (1977) que o poder disciplinar exercido por intermédio da arquitetura escolar e, da mesma forma, o controle da gestão escolar sobre o professor e o aluno pelo "olhar panóptico" demonstram de forma clara como a disciplina faz "[...] funcionar o espaço escolar como uma máquina de ensinar, mas também de vigiar, de hierarquizar, de recompensar" (FOUCAULT, 1977, p. 134). De acordo com o autor:

[...] o corpo, do qual se requer que seja dócil até em suas mínimas operações, opõe e mostra as condições de funcionamento próprio a um organismo. O poder disciplinar tem por correlato uma individualidade não só analítica e 'celular', mas também natural e "orgânica" (FOUCAULT, 1977, p. 141).

Esse poder disciplinar não almeja reter as forças, mas sim interligá-las, multiplicá-las e utilizá-las; para sua concretização, utiliza-se dessa vigilância hierárquica e de outros meios coercitivos de punição.

Outro mecanismo de poder disciplinar descrito por Foucault nas escolas são os exames ou provas. Por meio deles o professor conhece seus alunos, descritos, mensurados, comparados a outros; treinados, classificados, normalizados. "O exame combina as técnicas da hierarquia que vigia e a sanção que normaliza. É um controle normalizante, uma vigilância que permite qualificar, classificar e punir" (FOUCAULT, 1977, p. 164).

Nessas circunstâncias, nas escolas a aplicação de exames envolve todo um ritual que vai desde a padronização de sua estética até a conduta disciplinar e temporal. Os exames são aplicados em classes com alunos em ordem alfabética, enfileirados, com horários mínimos e máximos para término, com a proibi- 
ção de qualquer conversa ou gesto. $\mathrm{O}$ exame deve ser feito de maneira sistemática e objetiva. Esse ritual renova constantemente o poder, demonstra a força que a disciplina possui no cotidiano escolar. O exame compara os alunos e permite analisá-los e, se necessário, sancioná-los. Por ele obtém-se o conhecimento sobre o aluno, sobre suas aptidões e deficiências, sobre sua evolução ou desvio. Esse método pressupõe "[...] um mecanismo que liga certo tipo de formação de saber a certa forma de exercício do poder” (FOUCAULT, 1977, p. 166), o que nos leva à compreensão de que o exame representa uma das peças fundamentais para a edificação de uma pedagogia do controle de que na instituição escola o poder disciplinar torna-se natural e legítimo. Educar significa ensinar, qualificar, esclarecer, mas também disciplinar, vigiar e punir.

Ainda Foucault (1977) destacou que a escola, com sua técnica disciplinar, faz com que os atores escolares aceitem o poder de punir e de serem punidos. Nessa perspectiva, o poder disciplinar encontra um lugar propício nos discursos e nas ações de seus líderes, sendo a disciplina o protagonista das relações que compõem o universo escolar.

\section{PRISÃO E ESCOLA COMO INSTITUIÇÕES TOTAIS}

Outro autor que se deteve no estudo da dinâmica das instituições prisional e escolar foi Erving Goffman (1922-1982). Por contribuir com a produção científica não apenas da Sociologia e da Antropologia, como também da Psicologia Social, Psicanálise, Comunicação Social, Linguística, Literatura, Ciências da Saúde, dentre outras, ficou conhecido como um dos expoentes das Ciências Sociais do século XX.

Sempre buscando inovar na forma de produção do conhecimento científico, Goffman não escapou de severas críticas dos oposicionistas ao seu pensamento e à forma tão singular de investigação dos fenômenos sociais. Uma de suas características, "o pesquisador herói”, é considerada uma herança da tradição da Escola de Chicago.

As especificidades de seus estudos encontram-se na forma pela qual enveredava no campo de pesquisa para coletar dados, o que lhe conferiu o traço heroico. Internou-se por um ano (1955-1956) no Hospital Psiquiátrico Santa Elizabeth, localizado na cidade de Washington, Estados Unidos, uma instituição federal que possuía pouco mais de 7000 internos, objetivando conhecer o mundo interno de um hospital para doentes mentais e definir uma versão sociológica da estrutura do Eu. Goffman ainda trabalhou em um cassino, em Nevada, Estados Unidos, para estudar as artimanhas dos jogos e dos jogadores, as- 
sim como buscou analisar e refletir sobre as concepções de formação dos precursores da Escola de Chicago, principalmente de um dos seus maiores expoentes, o sociólogo norte-americano Robert Park ${ }^{4}$.

Este viria a influenciar decisivamente os princípios metodológicos de suas investigações, as quais tomavam como condição imprescindível a interação entre pesquisador e sujeito da pesquisa. Além disso, influenciado pela tradição etnográfica presente na antropologia produzida por Polaco Bronislaw Malinowski ${ }^{5}$, deteve-se no estudo das interações sociais ocorridas no cotidiano, trazendo à tona um complexo sistema de relações.

Pode-se afirmar que o centro das análises realizadas por Goffman está na observação de gestos, olhares, posicionamentos e verbalizações apresentadas pelos participantes de um encontro social enquanto sujeitos imersos em uma mesma análise, sem que ninguém ocupe um lugar proeminente.

Ao estudar e analisar criticamente o cotidiano de instituições fechadas como manicômios, prisões e conventos traz à tona o modo como esse tipo de segregação atua sobre o indivíduo, permitindo formular o conceito de "instituição total", de "carreira moral", de "vida íntima da instituição". Nesse sentido, intitula uma instituição total como "[...] um local de residência e de trabalho onde um grande número de indivíduos com situação semelhante, separados da sociedade mais ampla, por considerável período de tempo, levam uma vida fechada e formalmente administrada" (GOFFMAN, 2015, p. 11).

Ainda o autor compreende que são os mecanismos de estruturação de uma instituição que vão determinar sua condição de instituição total e ocasionar consequências na formação do Eu do indivíduo que dela participa sob determinada condição. "As prisões servem como exemplo claro disso, desde que consideremos que os aspectos característicos de prisões podem ser encontrados em instituições cujos participantes não se comportaram de forma ilegal” (GOFFMAN, 2015, p. 11).

Para Goffman (2015), os atores sociais interagem nas esferas da vida cotidiana em diferentes espaços sociais e se relacionam com diferentes partici-

\footnotetext{
${ }^{4} \mathrm{O}$ trabalho de Park se destaca por seus estudos sobre relações de raça, migração, assimilação, movimentos sociais e desorganização social no espaço urbano. A concepção de formação do sociólogo defendida por Park e seus sucessores era focada numa prática pedagógica baseada na observação de campo, na coleta de dados e no uso de outros instrumentos que extrapolassem o uso de fontes secundárias, possibilitando ao estudante a imersão na realidade social a fim de elaborar suas próprias análises. Ver em: Ralph H. Turner, Robert E. Park: On Social Control and Collective Behavior (Chicago: University of Chicago Press, 1967), uma antologia de textos de Park.

${ }^{5}$ Compreendia que o etnógrafo deveria apreender o ponto de vista do sujeito, chamado por ele de nativo, seu relacionamento com a vida, sua visão de mundo. Ver em: MALINOWSKI , B. Argonautas do pacífico ocidental. 2 ed. São Paulo: Abril Cultural; 1978.
} 
pantes e sob distintas hierarquias sem um plano racional geral. Entretanto, ao ser inserido em uma instituição social um ator passa a agir num mesmo lugar, com um determinado grupo de pessoas e sob tratamento, obrigações e regras iguais de realização das atividades impostas.

Quando uma determinada instituição social é estruturada para atender pessoas em situações semelhantes, em condição de confinamento por um determinado período de tempo e impondo-lhe a restrição da liberdade mediante uma rigorosa administração, ela apresenta a característica de ser fechada.

[...] seu fechamento ou seu caráter total é simbolizado pela barreira à relação social com o mundo externo e por proibições à saída que muitas vezes estão incluídas no esquema físico -, por exemplo, portas fechadas, paredes altas, arame farpado, fossos, água, florestas ou pântanos [...]. As instituições sociais de nossa sociedade podem ser, grosso modo, enumeradas em cinco agrupamentos. Em primeiro lugar, há instituições criadas para cuidar de pessoas que, segundo se pensa, são incapazes e inofensivas; nesse caso estão as casas para cegos, velhos, órfãos e indigentes. Em segundo lugar, há locais estabelecidos para cuidar de pessoas consideradas incapazes de cuidar de si mesmas e que são também uma ameaça à comunidade, embora de maneira não intencional; sanatório para tuberculosos; hospitais para doentes mentais e leprosários. Um terceiro tipo de instituição total é organizado para proteger a comunidade contra perigosos intencionais, e o bem-estar das pessoas assim isoladas não constitui o problema imediato: cadeias, penitenciárias, campos de prisioneiros de guerra, campos de concentração. Em quarto lugar, há instituições estabelecidas com a intenção de realizar de modo mais adequado alguma tarefa de trabalho, que se justificam apenas através de tais fundamentos instrumentais: quartéis, navios, escolas internas, campos de trabalho, colônias e grandes mansões (do ponto de vista dos que vivem nas moradias de empregados). Finalmente, há os estabelecimentos destinados a servir de refúgio do mundo, embora muitas vezes sirvam também como locais de instruções para os religiosos, entre exemplo de tais instituições, é possível citar abadias, mosteiros, conventos e outros claustros [...] (GOFFMAN, 2015, p. 16-17).

Com base nessa citação, a prisão é enquadrada no terceiro tipo de instituição total, a qual é destinada à proteção da sociedade dos atores sociais considerados perigosos intencionais. Goffman (2015) explicita que nas instituições totais, como as prisões, o preso chega ao estabelecimento com uma concepção de si mesmo, constituída por intermédio de algumas disposições legais do seu 
mundo doméstico. Ao entrar é imediatamente desvinculado do apoio recebido por tais disposições. Não por acaso, “dar início uma série de rebaixamento, degradações, humilhações e profanos do eu” (GOFFMAN, 2015, p. 24). Nesse momento, seu Eu é sistematicamente mortificado.

O processo de mortificação do Eu, no caso específico dos sujeitos internados nas prisões, inicia-se com a privação de bens materiais e estende-se para a perda de sua aparência usual, bem como dos instrumentos necessários para sua manutenção como roupas, pentes, agulhas e linhas, que poderão ser tirados dele ou a ele negados, para serem devolvidos se e quando sair. O autor salienta que o material substituto daquilo que foi retirado é quase sempre de um tipo inferior, mal ajustado, muitas vezes velho e igual para um grupo amplo e singular de internos (GOFFMAN, 2015).

Para exemplificar os impactos dessa substituição, Goffman (2015, p. 29) comenta as informações de um relatório que trata de prostitutas presas:

Em primeiro lugar existe um funcionário do chuveiro que as obriga a se despirem, tira suas roupas, faz com que tomem banho no chuveiro e recebam suas roupas da prisão — um par de sapatos pretos de amarras, com saltos baixos, dois pares de meias muito recomendadas, três vestidos de algodão, duas anáguas de algodão, duas calças, e um par de sutiens. Quase todos os sutiens estão frouxos e são inúteis. Não recebem cintas e nem cinto.

Além de as presas perderem seu conjunto de identidade, existe a desfiguração pessoal decorrente de mutilações diretas e permanentes do corpo, que vão de marcas e perdas de membros a terapias de choques, dando aos reclusos a sensação de que estão num ambiente que não garante sua integridade física.

Nas entrelinhas de sua descrição da instituição total prisão aponta que:

[...] nas prisões militares, os internados podem ser obrigados a ficar em posição de sentido, sempre que um policial entre no local. [...] Em algumas instituições prisionais encontramos a humilhação de curva-se para ser açoitado. [...] Nas prisões, a negação de oportunidades para relações heterossexuais pode provocar o medo de perda da masculinidade. [...] há outra forma de mortificação; a partir da admissão, ocorre uma espécie de exploração contaminadora. No mundo externo, o indivíduo pode manter objetos que se ligam aos seus sentimentos do eu -, por exemplo, seu corpo, suas ações imediatas, seus pensamentos e alguns de seus bens fora de contato com as coisas estranhas e contaminadoras. No entanto, 
nas instituições totais esses territórios do eu são violados; a fronteira que o indivíduo estabelece entre seu ser e o ambiente é invadido e as encarnações são profanadas. [...] as celas de prisão com barras de metal como parede permite essa exposição. Talvez o tipo mais evidente de exposição contaminadora seja a de tipo diretamente físico - a sujeira ou a mancha do corpo ou de outros objetos intimamente identificados como o eu. Às vezes isso inclui uma ruptura das usuais disposições do ambiente para isolamento da fonte de contaminação -, por exemplo, precisar esvaziar o "vaso sanitário" [...] (GOFFMAN, 2015, p. 30-32).

Como se observa, a etnografia da prisão apresentada por Goffman é extremamente rica e detalhista, traz à tona as formas mais impensadas usadas pelos seus dirigentes para desconstrução do Eu e do próprio ser social. As condições das celas são representativas de como o espaço prisional descrito por Goffman contribuem para o contato mútuo e a exposição entre os internos, uma vez que:

A cela é usualmente nua, e mal contém o grupo que ali é colocado. Pode haver uma plataforma para dormir, mas todos os presos dormem no chão; quando todos se deitam, todas as polegadas do chão podem estar ocupadas. A atmosfera é de extrema promiscuidade. A vida reservada é impossível (GOFFMAN, 2015, p. 36).

Outras três vias de exposição são descritas por esse autor: o sistema de apelidos para os internos, aplicado por dirigentes e outros internos que se arrogam o direto de empregar uma forma íntima de chamar a pessoa. Outra via é de aceitação de alimentos estranhos e poluídos, que quase sempre ocorre do contato de outro interno com o alimento. E, por fim, quando se coloca um estranho em contato com a relação individual íntima daqueles que são significativos para ele, por exemplo, ao terem violadas, lidas ou censuradas suas correspondências. Ainda nessa via, está descrito o caráter obrigatório das visitas em que numa mesma sala estão os presos e seus visitantes e o guarda que cuida da vigilância, não havendo privacidade alguma, mesmo quando o preso está encontrando sua mulher.

Goffman também observou que nas instituições totais, em especial na prisão, existe um sistema de ajustamento que poderíamos chamar ajustamento secundário. Trata-se de práticas realizadas no interior das prisões que não desafiam diretamente os dirigentes, mas que permitem que os internos consigam re- 
alizar desejos proibidos ou obtenham, por meios proibidos, as satisfações permitidas.

De acordo com Goffman (2015, p. 54), "Tais práticas recebem vários nomes: "os ângulos", "saber que apito tocar", "conivências", "tratos". Tais adaptações aparentemente atingem seu florescimento completo nas prisões, mas, evidentemente, outras instituições totais também as possuem”. Para o autor, ajustamentos secundários dão aos internos uma espécie de sensação de autonomia; para garantir a invisibilidade desses ajustamentos, o grupo de internos cria algum tipo de código e alguns meios de controle social informal para impedir que um internado informe a equipe dirigente quanto aos ajustamentos secundários de outro.

Observou que os internos criam diferentes estratégias para se adaptarem às condições de internado e para organização do $\mathrm{Eu}$, distintos processos que variam e se multiplicam. Sinaliza o autor que, "Para o homem que sai da prisão, pode haver única forma de liberdade. "condicionar" com a obrigação de apresentar-se regularmente e afastar-se dos círculos de que participava quando entrou na prisão" (GOFFMAN, 2015, p. 54). Entretanto, aponta que, com o passar do tempo na instituição, dentro daquele indivíduo que foi rejeitado, mesmo anteriormente ao seu ingresso, cresce uma enorme rejeição com relação àqueles que um dia o deixaram de lado. Apesar disso, muitas vezes há o desejo do interno de não querer sair da instituição, o que pode ocorrer por diversos motivos, dentre os quais podemos destacar o preconceito do qual esse indivíduo será portador justamente pelo fato de ter pertencido aquele local.

Finalmente, na sua análise, Goffman afirma que os problemas sociais estão subjacentes à estrutura de todas as instituições totais. Assim como a prisão, a escola também ganha o desenho de uma instituição total. Para ele, sua estrutura fechada, seus dirigentes agindo em nome de regras preestabelecidas e com a preocupação de preencher o tempo dos alunos com atividades também predeterminadas são sinais de um regime de confinamento.

Nas suas descrições da escola como instituição total,

[...] as regras são muitas vezes ligadas a uma obrigação de executar a atividade regulada em uníssono com grupos de outros internados. É isso que às vezes se denomina arregimentação. [...] essas regras difusas ocorrem num sistema de autoridade escalonada: qualquer pessoa da classe dirigente tem alguns direitos para impor disciplina a qualquer pessoa da classe de internados, o que aumenta nitidamente a possibilidade de sanção (GOFFMAN, 2015, p. 64). 
A educação para boas maneiras, que segue os padrões estabelecidos pelos contratos sociais, deve ser incorporada pelos internos de modo a evitar qualquer tipo de sanção. Nesse processo, dá-se o abandono do Eu. A necessidade de pedir permissão para executar determinadas ações que antes eram realizadas banalmente, tais como ir ao banheiro, fato que perturba a economia de ação exterior e psíquica de um indivíduo, perfeitamente expressas nas palavras de Goffman (2015, p. 49) da seguinte maneira: “A mortificação ou mutilação do eu tendem a incluir aguda tensão psicológica para o indivíduo, mas para um indivíduo desiludido do mundo ou com sentimento de culpa, a mortificação pode promover alívio psicológico [...]”.

Relata o autor que, ao mesmo tempo em que ocorre essa mortificação, o internado, no caso da instituição escola, começa a receber instrução formal e informal a respeito do que é denominado sistema de privilégios. Ou seja, a instituição possui uma série de regras da casa que são conhecidas de maneira informal, depois de muito sofrimento. Tal processo doloroso e humilhante de aprendizado acontece durante a longa carreira moral em que se insere, obrigatoriamente, o indivíduo que faz parte da instituição total.

\section{CONSIDERAÇÕES FINAIS}

As prisões emergiram de uma imposição do próprio contrato social e da mudança da legislação penal. Assim sendo por meio da sua aplicação, surgiram os sistemas penitenciários para fazer cumprir as sentenças criminais e normas dos Códigos Penais e demais regulamentos, em lugares determinados pelos órgãos públicos da Justiça e outros de cada país.

Nos escritos de Foucault e de Goffman, a prisão e a escola são entendidas como instituições de sequestro ou disciplinares e totais. Isto é, instituições que têm a sua própria organização e dotadas de certa racionalidade para fazer acontecer a punição aos corpos e às mentes, além da sujeição às suas regras de funcionamento. $\mathrm{O}$ que significa dizer que nestas instituições, o problema da disciplina e do poder, não é simplesmente institucional, mas passa pelo reconhecimento de um conjunto de dispositivos, de mecanismos e técnicas disciplinares que são presentes de forma capilar em toda uma sociedade. Ou ainda que, as instituições de sequestro e total, como (a prisão e a escola) são muito mais que uma forma arquitetural, é uma forma social. Podem ser compreendidas como um aparato do Estado, que tem por finalidade de assujeitamento e são constituídas por dispositivos de poder, mecanismos de normatização que estão, ao mesmo tempo, dentro e fora dessas instituições. 
Embora a dureza das análises de Foucault e de Goffman nos levem a certo ceticismo, as suas obras nos direcionam a refletir que é preciso que o modelo do sistema penitenciário progressivo em vigor no século XXI, mude, para que também melhore as condições de trabalho nas escolas instaladas nas prisões, e logo, a formação escolar às pessoas presas.

\section{REFERÊNCIAS}

ABREU, A. A. Educação entre grades: um estudo sobre a educação penitenciária no amapá. 2008. Dissertação (Mestrado em Educação) - Universidade Federal de São Carlos, São Carlos, 2008.

BRASIL. Lei de Execução Penal. Lei n. 7.210, de 11 de julho de 1984: institui a Lei de Execução Penal. Brasília: Câmara dos Deputados, Coordenação de Publicações, 2008. (Série Legislação, n. 11).

Lei $\mathbf{n}^{\circ} \mathbf{1 3 . 1 6 3}$ de 9 de setembro de 2015. Modifica a Lei $\mathrm{n}^{\circ} 7.210$ de 11 de julho de 1984 - Lei de Execução Penal, para instituir o ensino médio nas penitenciárias. Disponível em: < http://www.planalto.gov.br/ccivil 03/ Ato2015-2018/2015/Lei/L13163.htm>. Acesso: 05 jan. 2019.

Lei $\mathbf{n}^{\circ} \mathbf{1 2 . 4 3 3}$ de 29 de junho de 2011. Altera a Lei no 7.210, de 11 de julho de 1984 (Lei de Execução Penal), para dispor sobre a remição de parte do tempo de execução da pena por estudo ou por trabalho. Disponível em: $<$ http://www.planalto.gov.br/ccivil 03/ ato2011-2014/2011/lei/ 112433.htm>. Acesso: 05 jan. 2019.

. Emenda Constitucional n ${ }^{\circ} 14$ de 12 de setembro de 1996. Disponível em: < http://www.planalto.gov.br/ccivil 03/constituicao/Emendas/ Emc/emc14.htm>. Acesso: 05 jan. 2019.

. Ministério da Educação e Cultura. Parecer CNE/CEB No 2/2010.

Diretrizes Nacionais para a oferta de educação de jovens e adultos em situação de privação de liberdade nos estabelecimentos penais. Disponível em: $<\underline{\text { http://portal.mec.gov.br/index.php? }}$ option $=$ com content $\&$ view $=$ article\&id $=14906>$ > Acesso: 05 jan. 2019.

. Ministério da Saúde. Plano Nacional de Saúde no Sistema Penitenciário. Brasília: s.e, 2004. Disponível em < http://bvsms.saude.gov.br/ bvs/publicacoes/cartilha pnssp.pdf>. Acesso: 05 jan. 2019. 
. Ministério da Justiça e Segurança Pública. Resolução no 14, de 11 de novembro de 1994. Estabelece as regras mínimas para o tratamento do preso no Brasil. Diário Oficial da União, Brasília, 02 de dezembro de 1994.

BROBJER, T. H. Nietzsche's Philosophical Context: an intellectual biography. Chicago: University of Illinois Press, 2008.

CENTRO DOS DIREITOS DO HOMEM DAS NAÇÕES UNIDAS. Regras Mínimas para o Tratamento de Recuclos, 1955. Disponível em: < $\underline{\text { http:// }}$ pfdc.pgr.mpf.mp.br/atuacao-e-conteudos-de-apoio/legislacao/sistema-prisional/sistema-prisional/regras minimas.pdf > . Acesso: 05 jan. 2019.

CLEMMER, D. The prison community. 3.ed. New York: Rineart the Winston, 1960.

COHEN-SOLAL, A. Sartre: uma biografia. Trad. de Milton Persson. 2.ed. Porto Alegre: L\&PM Editores, 2008.

FALCADE-PEREIRA, I. A.; ASINELLI-LUZ, A. O espaço prisional: estudos, pesquisas e reflexões de práticas educativas. Curitiba: Appris, 2014.

FOUCAULT, M. Microfísica do poder. Rio de Janeiro: Edições Graal, 1986.

. Vigiar e punir: história da violência nas prisões. 21.ed. Petrópolis:

Vozes, 1977.

GOFFMAN, E. Manicômios, prisões e conventos. São Paulo: Perspectivas, 2015.

JULIÃO, E. F. Políticas de Execução Penal no Brasil: questões, avanços e perspectivas. In: JULIÃO, E. F.; RITA, R. P. S. (Org.). Privação de liberdade: desafios para políticas de direitos humanos. Jundiaí: Paco, 2015, p. 11-40.

. Sistema penitenciário brasileiro: a educação e o trabalho na política de execução penal. Petrópolis: FAPERJ, 2012.

MALINOWSKI , B. Argonautas do pacífico ocidental. 2.ed. São Paulo: Abril Cultural, 1978.

ONOFRE, E. M. C. A escola da prisão como espaço de dupla inclusão: no contexto e para além das grades. Polyphonía, Goiânia, Vol. 22, n. 1, p. 109 120, Jan./Jun. 2011.

SANTOS, S. A educação escolar no sistema prisional sob a ótica de detentos. Dissertação (Mestrado em Educação) - Pontifícia Universidade Católica de São Paulo, São Paulo, 2002. 
SYKES, G. M. The society of captives: a study of a maximum security. 11.ed. New Jersey: Princeton University Press, 1999.

TEIXEIRA, M. C. S. Antropologia, cotidiano e educação. Rio de Janeiro: Imago, 2007.

THOMPSON, E. P. Costumes em comum: estudos sobre a cultura popular tradicional. São Paulo: Companhia das Letras, 2002.

UNESCO. World Declaration on Education for all. Jomtien: Unesco, 1990. VASQUEZ, E. L. Sociedade cativa. Entre cultura escolar e cultura prisional: uma incursão pela ciência penitenciária. 2008. Dissertação (Mestrado em História da Ciência) - Pontifícia Universidade Católica de São Paulo, São Paulo, 2008. 